\title{
Activation of RXR by bexarotene inhibits inflammatory conditions in human rheumatoid arthritis fibroblast-like synoviocytes
}

\author{
YU LI $^{1}$, QUNZHI XING ${ }^{2}$, YUANZHANG WEI ${ }^{1}$, LEI ZHAO $^{1}$, PEI ZHANG ${ }^{1}$, XUECHANG HAN $^{2}$ and JING WANG $^{1}$ \\ ${ }^{1}$ Ache Department and ${ }^{2}$ Department of Anesthesiology, First Affiliated Hospital of Henan \\ University of Science and Technology, Luoyang, Henan 471003, P.R. China
}

Received April 16, 2019; Accepted June 26, 2019

DOI: $10.3892 /$ ijmm.2019.4336

\begin{abstract}
Rheumatoid arthritis (RA) is a debilitating joint disease characterized by chronic inflammation, pathologic alteration of fibroblast-like synoviocytes (FLS), destruction of cartilage and bone, and the formation of an invasive pannus. RA-FLS exhibit increased proliferation and resistance to apoptosis. The retinoid $\mathrm{X}$ receptor ( $\mathrm{RXR}$ ) has a role in regulating cell cycle, differentiation and apoptosis, and agonism of RXR has been investigated as a treatment strategy in several types of cancer. However, there is little research on the effects of $\mathrm{RXR}$ agonism in other diseases. Bexarotene is a novel selective RXR ligand used in the treatment of T-cell lymphoma. In the present study, bexarotene was used to investigate the involvement of RXR in tumor necrosis factor- $\alpha$ (TNF- $\alpha$ )-induced RA conditions in human FLS. To the best of our knowledge, this is the first time that RXR has been demonstrated to be expressed in FLS and to be downregulated in response to TNF- $\alpha$ stimulation. The present study also demonstrated that bexarotene exerted an anti-inflammatory effect by downregulating expression of interleukin (IL)-6, IL-8, monocyte chemoattractant protein-1, and high mobility group box-1. Notably, bexarotene also rescued the TNF- $\alpha$-induced downregulation of the anti-inflammatory cytokines IL-4 and transforming growth factor- $\beta 1$. Bexarotene treatment exhibited a potential protective effect against cartilage degradation by downregulating the expression of matrix metalloproteinase (MMP)-1, MMP-3 and MMP-13. In addition, the present results demonstrated that the effects of bexarotene were mediated through the p38 mitogen-activated protein kinase/nuclear factor- $\kappa \mathrm{B}$ pathway, via inhibition of $\mathrm{p} 38$ protein and the inhibitor $\alpha$ of $\kappa \mathrm{B}$ phosphorylation. Taken together, the present findings demonstrated the potential of RXR agonism using bexarotene as a treatment against the development and progression of RA.
\end{abstract}

Correspondence to: Dr Yu Li, Ache Department, First Affiliated Hospital of Henan University of Science and Technology, 24 Jinghua Road, Luoyang, Henan 471003, P.R. China

E-mail: yuli0246@163.com

Key words: rheumatoid arthritis, fibroblast-like synoviocytes, bexarotene, retinoid $\mathrm{X}$ receptor

\section{Introduction}

Rheumatoid arthritis (RA) is among the most common autoimmune disorders and is characterized by painful, swollen joints, the formation of an invasive pannus, chronic articular inflammation, and degradation of cartilage and bone (1-3). Fibroblast-like synoviocytes (FLS) are the most abundant cell type composing the intimal lining of the synovium. In normal conditions, the synovial membrane facilitates smooth articulation of the joint, while in RA, FLS take on an invasive pathological phenotype. RA-FLS secrete proinflammatory cytokines and degradative enzymes that promote chronic inflammation of the joint, as well as cartilage and bone destruction (4). It is well-established that secretion of interleukins (ILs) including IL- 6 and IL- 8 by FLS contributes to inflammation and progression of RA (5-7). Monocyte chemoattractant protein (MCP)-1 is an important chemokine that recruits macrophages to infiltrate the synovium (8). Matrix metalloproteinases (MMPs) are essential to cartilage remodeling, but increased expression of MMPs, including MMP-1, MMP-3 and MMP-13, is observed in RA. Overexpression of these enzymes drives excessive cartilage degradation and destruction of the joint by cleaving type II collagen and aggrecan $(9,10)$. Together, these processes create the ideal conditions for the formation of an invasive pannus. In normal physiology, the deleterious effects of cytokines, chemokines and degradative enzymes are tightly regulated by complementary anti-inflammatory cytokines, such as IL-4. Previous studies have demonstrated that IL-4 is lacking in the RA synovium and treatment with IL-4/IL-10 exerts significant protective effects against cartilage destruction $(11,12)$. Expression of transforming growth factor (TGF)-1 $\beta$ has also been demonstrated to exert a protective effect in RA by inhibiting expression of proinflammatory cytokines $(12,13)$.

Tumor necrosis factor (TNF)- $\alpha$ is another major cytokine involved in RA. TNF- $\alpha$ is upregulated in the synovium and synovial fluid of patients with RA and is recognized as serving a pivotal role in the pathogenesis of RA by inducing oxidative stress, production of proinflammatory cytokines and chemokines, and expression of degradative enzymes by FLS, thereby promoting pannus invasion and sustained inflammation (14-16). Anti-TNF- $\alpha$ and anti-IL-6 therapies have become a cornerstone of RA treatment. However, not all patients respond to these strategies (17). Recently, treatment methods that modulate multiple cytokines by targeting signaling 
pathways through specific receptors have been receiving attention as a novel treatment approach for RA (17). Bexarotene is a specific retinoid $\mathrm{X}$ receptor (RXR) subfamily agonist that was approved by the Food and Drug Administration (FDA) for the treatment of T-cell lymphoma in 1999. Bexarotene has been noted to have a low occurrence of retinoid side effects $(18,19)$. RXRs regulate cell apoptosis and exert antiangiogenic effects, thereby serving as a novel treatment target for various types of cancers (19). In the present study, the effects of bexarotene treatment were investigated in primary human FLS exposed to TNF- $\alpha$. The results demonstrated that specific agonism of RXR by bexarotene significantly suppressed TNF- $\alpha$-induced release of IL-6, IL-8 and MCP-1. In addition, bexarotene treatment resulted in a downregulation of expression of MMPs, increased levels of the anti-inflammatory cytokines IL-4 and TGF- $\beta 1$, and attenuation of oxidative stress. Notably, the present study indicated that these effects of RXR agonism were mediated through the p38 mitogen-activated protein kinase (MAPK)/nuclear factor (NF)- $\mathrm{B}$ signaling pathway.

\section{Materials and methods}

Cell culture and treatment. Human subject studies were designed in accordance with the World Medical Association Declaration of Helsinki Ethical Principles for Medical Research Involving Human Subjects. Experimental procedures were approved by the Institutional Ethics Committee at the First Affiliated Hospital of Henan University of Science and Technology. Written informed consent was obtained from all of the participants. Primary human FLS were isolated as previously described (20). The tissues were collected and cut into small pieces in a cell culture hood before being digested with $0.2 \%$ collagenase (Sigma-Aldrich; Merck KGaA) overnight in a $37^{\circ} \mathrm{C}$ and $5 \% \mathrm{CO}_{2}$ humidified incubator. The isolated cells were then seeded into $10 \mathrm{~cm}$ Eppendorf cell culture dishes in DMEM (Thermo Fisher Scientific, Inc.) supplemented with $10 \%$ fetal calf serum (FCS; Gibco; Thermo Fisher Scientific, Inc.) and antibiotics (penicillin $0.1 \mathrm{mg} / \mathrm{ml}$, gentamycin $0.05 \mathrm{mg} / \mathrm{ml}$, and amphotericin B $50 \mathrm{ng} / \mathrm{ml}$ ). The medium was changed every 3 days, passaged twice, and $2 \times 10^{5}$ cells were seeded into each well of a 6 -well dish for subsequent experiments. FLS were treated with $10 \mathrm{ng} / \mathrm{ml} \mathrm{TNF-} \alpha$ in the presence or absence of 150 and $300 \mathrm{nM}$ bexarotene for $24 \mathrm{~h}$.

RNA isolation and reverse transcription-quantitative PCR $(R T-q P C R)$ analysis. After the indicated treatments, cells were washed twice with cold Dulbecco's phosphate-buffered saline (DPBS) and treated with $0.5 \mathrm{ml}$ TRIzol (cat. no. 15596026; Thermo Fisher Scientific, Inc.). Total RNA was isolated following the protocol from the manufacturer. A DNase (Thermo Fisher Scientific, Inc.) treatment was included in the end, following the supplier's protocol. The RNA concentration was measured using a NanoDrop 2000 spectrophotometer. Two $\mu \mathrm{g}$ total RNA was adjusted to the same concentration before being reverse-transcribed into cDNA using a Verso 1-Step RT-PCR kit (Applied Biosystems; Thermo Fisher Scientific, Inc.) in accordance with the manufacturer's instructions. The qPCR SYBR green mix and cycling conditions were used as previously described (21). qPCR experiments were performed using a Roche LightCycler 480 (Roche Applied Science) with a 384-multiwell format. The
qPCR was performed with the following conditions: A 5 min denaturation step at $94^{\circ} \mathrm{C}, 40$ cycles of a $30 \mathrm{sec}$ denaturation step at $94^{\circ} \mathrm{C}$, a $30 \mathrm{sec}$ annealing step at $56^{\circ} \mathrm{C}$, and a $45 \mathrm{sec}$ extension step at $72^{\circ} \mathrm{C}$. Relative fold changes of target gene expression were then calculated using the $2^{-\Delta \Delta \mathrm{Cq}}$ method (21). The following primers were used in the present study: RXR, forward 5'-CATGTTTGACTGTATGGATG-3' and reverse 5'-AGCCCTTACATCCCTCACAG-3'; IL-6, forward 5'-GGT ACATCCTCGACGGCATCT-3' and reverse 5'-GTGCCTCTT TGCTGCTTTCAC-3'; IL-8, forward 5'-TTTCTGTTAAAT CTGGCAACCCTAGT-3' and reverse 5'-ATAAAGGAGAAA CCAAGGCACAGT-3'; MCP-1, forward 5'-ATGCAATCAATG CCCCAGTC-3' and reverse 5'-TGCAGATTCTTGGGTTGT GG-3'; MMP-1, forward 5'-CCTAGTCTATTCATAGCTAAT CAAGAGGATGT-3' and reverse 5'-AGTGGAGGAAAGCTG TGCATAC-3'; MMP-3, forward 5'-CCTCTATGGACCTCC CACAGAATC-3' and reverse 5'-GGTGCTGACTGCATCGAA GGACAAA-3'; MMP-13, forward 5'-CTGGCCTGCTGGCTC ATGCTT-3' and reverse 5'-CCTCAGAAAGAGCAGCATCGA TATG-3'; IL-4, forward 5'-GCCACCATGAGAAGGACACT-3' and reverse 5'-ACTCTGGTTGGCTTCCTTCA-3'; TGF- $\beta 1$, forward 5'-CCCTGGACACCAACTATTGC-3' and reverse 5'-TGCGGAAGTCAATGTACAGC-3'; and GAPDH, forward 5'-ACCCCTTCATTGACCTCAAC-3' and reverse 5'-CTTGAC GGTGCCATGGAATT-3'.

Western blot analysis. Total protein was isolated from FLS with a Total Protein Extraction kit (Thermo Fisher Scientific, Inc.). Protein concentration was determined using the bicinchoninic acid method (Sigma-Aldrich; Merck KGaA). Equal amounts of protein $(20 \mu \mathrm{g})$ from cells were loaded onto a $10 \%$ SDS-PAGE and transferred to a polyvinylidene fluoride membrane (EMD Millipore) (22). Membranes were blocked with $5 \% \mathrm{BSA}$ in TBS for $2 \mathrm{~h}$ at room temperature and then incubated with primary antibodies at $4^{\circ} \mathrm{C}$ overnight. After three washes with TBST, membranes were incubated with horseradish peroxidase (HRP)-conjugated secondary antibody at room temperature (RT) for $2 \mathrm{~h}$. Blots were detected using the Immobilon Western Chemiluminescent HRP Substrate system (Merck KGaA). The following primary antibodies were used in this study: RXR (cat. no. sc-553; 1:2,000; Santa Cruz Biotechnology, Inc.), tubulin (cat. no. NB600-936; 1:5,000; Novus Biologicals, Ltd.), p38 (cat. no. 8690; 1:3,000; Cell Signaling Technology, Inc.), phosphorylated (p-) p38 (cat. no. 4511; 1:1,000; Cell Signaling Technology, Inc.), inhibitor $\alpha$ of $\kappa \mathrm{B}(\mathrm{I} \kappa \mathrm{B} \alpha$; cat. no. 4814; 1:1,000; Cell Signaling Technology, Inc.), p-IкB $\alpha$ (cat. no. 2859; 1:1,000; Cell Signaling Technology, Inc.), NF-кB (cat. no. 6956; 1:3,000; Cell Signaling Technology, Inc.) and lamin B1 (cat. no. 13435; 1:5,000; Cell Signaling Technology, Inc.). The following secondary antibodies were used: anti-rabbit HRP-linked secondary antibody (cat. no. 7074; 1:3,000; Cell Signaling Technology, Inc.) and anti-mouse HRP-linked secondary antibody (cat. no. 7076; 1:3,000; Cell Signaling Technology, Inc.).

Measurement of intracellular reactive oxygen species $(R O S)$. The patterns of oxidative stress in FLS were assessed by measuring intracellular ROS. FLS were treated with $10 \mathrm{ng} / \mathrm{ml} \mathrm{TNF}-\alpha$ in the presence or absence of 150 and $300 \mathrm{nM}$ bexarotene for $24 \mathrm{~h}$. After the indicated treatments, 

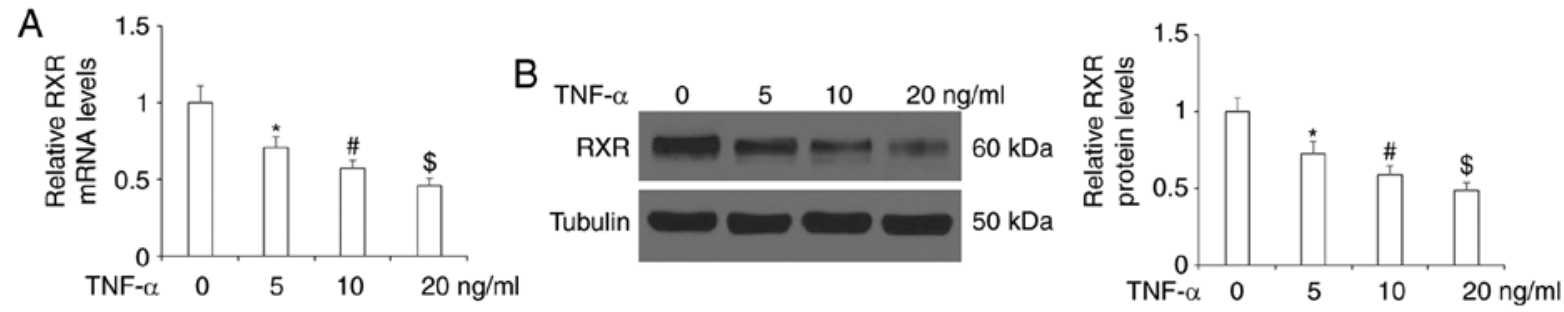

Figure 1. TNF- $\alpha$ reduces the expression of RXR in human FLS. FLS were treated with $0,5,10$ or $20 \mathrm{ng} / \mathrm{ml}$ TNF- $\alpha$ for $24 \mathrm{~h}$. (A) mRNA expression levels of RXR were measured by reverse transcription-quantitative PCR analysis. (B) Protein expression levels of RXR were measured western blot analysis. "P<0.01 vs. $0 \mathrm{ng} / \mathrm{ml} ;{ }^{\#} \mathrm{P}<0.01$ vs. $5 \mathrm{ng} / \mathrm{ml}$; and ${ }^{\mathrm{S}} \mathrm{P}<0.01$ vs. $10 \mathrm{ng} / \mathrm{ml}$. TNF- $\alpha$, tumor necrosis factor- $\alpha$; RXR, retinoid X receptor; FLS, fibroblast-like synoviocytes.

cells were incubated with $10 \mu \mathrm{M}$ 2',7'-dichlorodihydrofluorescein diacetate (DCFH-DA) for $30 \mathrm{~min}$ in the dark. With this assay, the reduced DCFH-DA gets oxidized and converted into fluorescent dichlorofluorescein by intracellular ROS (23). The fluorescent signals were visualized using a fluorescence microscope (Zeiss GmbH). Fluorescence intensity of ROS images was quantified using the software ImageJ version 1.51 (National Institutes of Health). Regions of interest (ROI) were defined and the average number of cells present in the ROI was counted. Then ROS activity was calculated as follows: Average ROS $=$ the integrated density value/average cell number.

ELISA. FLS were treated with $10 \mathrm{ng} / \mathrm{ml} \mathrm{TNF-} \alpha$ in the presence or absence of 150 and $300 \mathrm{nM}$ bexarotene for $24 \mathrm{~h}$. Supernatants were collected to examine the secretion of IL-6, IL-8, MCP-1, IL-4 and TGF- $\beta 1$. Cells were lysed and lysates were used to determine the levels of MMP-1, MMP-3 and MMP-13. Commercial ELISA kits (R\&D Systems, Inc.) were used for all the measurements (human IL-6, cat. no. D6050; human IL-8, cat. no. D8000C; human MCP-1, cat. no. DCP00; human TGF- $\beta 1$, cat. no. DB100B; human MMP-1, cat. no. DY901B; human MMP-3, cat. no. DMP300; and human MMP-13, cat. no. DY511), in accordance with the manufacturer's instructions.

Luciferase activity determination. FLS were seeded into 24-well plates. Twenty-four $\mathrm{h}$ later, NF- $\mathrm{\kappa B}$ reporter plasmids (Beyotime Institute of Biotechnology) and a Renilla luciferase plasmid (Promega Corporation) were transfected into cells using Lipofectamine 2000 (thermo Fisher Scientific, Inc.), in accordance with the manufacturer's instructions. At $24 \mathrm{~h}$ post-transfection, cells were treated with $10 \mathrm{ng} / \mathrm{ml}$ TNF- $\alpha$ in the presence or absence of 150 and $300 \mathrm{nM}$ bexarotene for $24 \mathrm{~h}$. Cells were then lysed, and the luciferase activity was measured using a Dual-Luciferase Reporter Assay System (Promega Corporation). The relative promoter activity was calculated as firefly luminescence/Renilla luminescence.

Nuclear protein extraction. The nuclear extracts of FLS were obtained using the NE-PER ${ }^{\mathrm{TM}}$ Nuclear and Cytoplasmic Extraction Reagent (cat. no. 78833; Thermo Fisher Scientific, Inc.), in accordance with the manufacturer's instructions. The nuclear protein lamin B1 was used as a control for the nuclear fraction.

Statistical analysis. All values are expressed as means \pm standard deviation. Statistical analysis was performed using SPSS version 18.0 software (SPSS, Inc.). Differences among the groups were detected using the one-way analysis of variance, followed by Bonferroni post-hoc test. $\mathrm{P}<0.05$ was considered to indicate a statistically significant difference.

\section{Results}

First, we determined whether RXR is expressed on human FLS. As shown by the results of RT-qPCR and western blot analyses in Fig. 1, RXR was expressed in FLS and its expression was significantly reduced at both the mRNA and protein levels upon exposure to TNF- $\alpha$. The inhibitory effect of TNF- $\alpha$ on RXR expression was dose-dependent. Next, the effects of RXR agonism on various factors of RA was investigated using bexarotene. Human FLS were treated with TNF- $\alpha$ in the presence or absence of bexarotene. As shown by the results of RT-qPCR in Fig. 2A, TNF- $\alpha$ stimulation increased the mRNA expression levels of IL-6, IL-8 and MCP-1 by 5.2-, 4.6- and 7.6-fold, respectively. Western blot analysis confirmed that TNF- $\alpha$ stimulation increased the protein expression levels of IL-6, IL-8 and MCP-1 by 4.5-, 4.3- and 7.1-fold, respectively (Fig. 2B). However, the expression of all three of these cytokines was reduced to roughly 2 -fold at the mRNA level (Fig. 2A) and 1.5- to 2-fold at the protein level (Fig. 2B) by treatment with bexarotene, compared with TNF- $\alpha$ stimulation alone. RT-qPCR and ELISA analyses were employed to determine the effects of RXR agonism on TNF- $\alpha$-induced expression of MMPs by FLS. Briefly, cells were exposed to TNF- $\alpha$ in the presence or absence of bexarotene. As shown in Fig. 3, TNF- $\alpha$ stimulation increased expression of MMP-1, MMP-3 and MMP-13 by 4.2-, 5.5- and 6.5-fold, respectively, at the mRNA levels and 3.8-, 4.5-, and 5.4-fold at the protein level. Notably, treatment with bexarotene reduced this TNF- $\alpha$-induced overexpression of these enzymes to $<2$-fold at both the mRNA and protein levels (Fig. 3).

Next, the present study investigated the effect of RXR agonism by bexarotene on the anti-inflammatory and antioxidant factors IL- 4 and TGF- $\beta 1$. As shown in Fig. 4, exposure to TNF- $\alpha$ reduced expression of IL- 4 and TGF- $\beta 1$ by roughly half at both the mRNA and protein levels. However, RXR agonism by bexarotene significantly restored the expression of these protective factors, almost to the levels of the control cells (Fig. 4). To investigate the effects of bexarotene on oxidative stress, ROS production was determined using the DCFH-DA assay. As shown in Fig. 5, ROS production was increased to $\sim 3.5$-fold upon exposure to TNF- $\alpha$, but treatment with bexarotene significantly ameliorated this effect. 

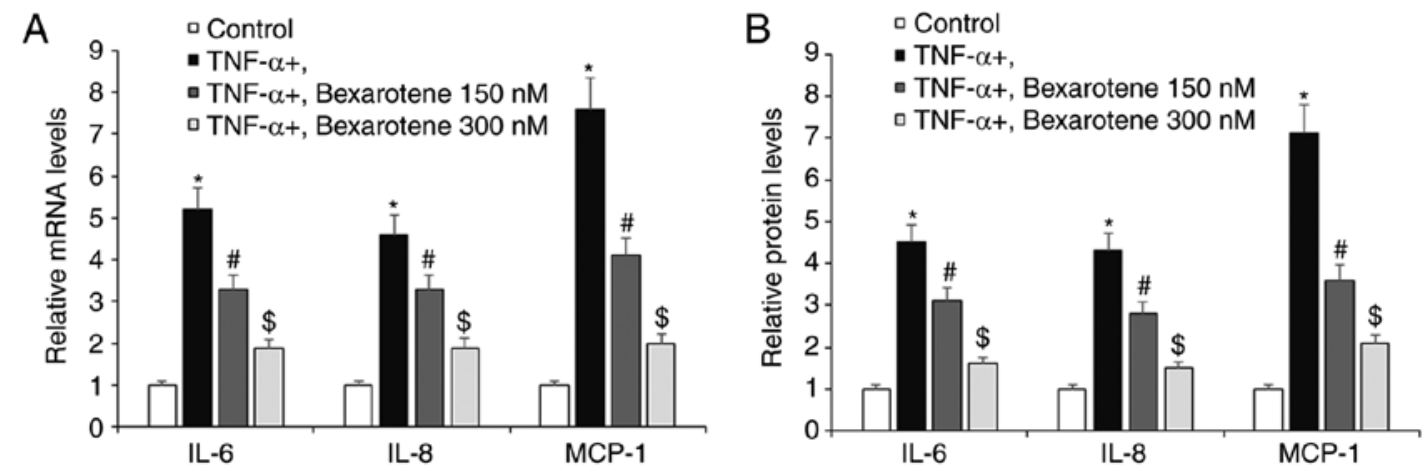

Figure 2. Bexarotene reverses the TNF- $\alpha$-induced production of proinflammatory cytokines in human FLS. FLS were treated with $10 \mathrm{ng} / \mathrm{ml}$ TNF- $\alpha$ in the presence or absence of 150 and $300 \mathrm{nM}$ bexarotene for $24 \mathrm{~h}$. (A) mRNA expression levels of IL-6, IL- 8 and MCP-1 were determined by reverse transcription-quantitative PCR analysis. (B) Secreted levels of L-6, IL-8 and MCP-1 were determined by ELISA. $\mathrm{P}<0.01$ vs. control; ${ }^{*} \mathrm{P}<0.01 \mathrm{vs}$. TNF- $\alpha$; and ${ }^{\mathrm{S}} \mathrm{P}<0.01$ vs TNF- $\alpha+$ bexarotene $150 \mathrm{nM}$. TNF- $\alpha$, tumor necrosis factor- $\alpha$; FLS, fibroblast-like synoviocytes; IL, interleukin; MCP-1, monocyte chemoattractant protein-1.
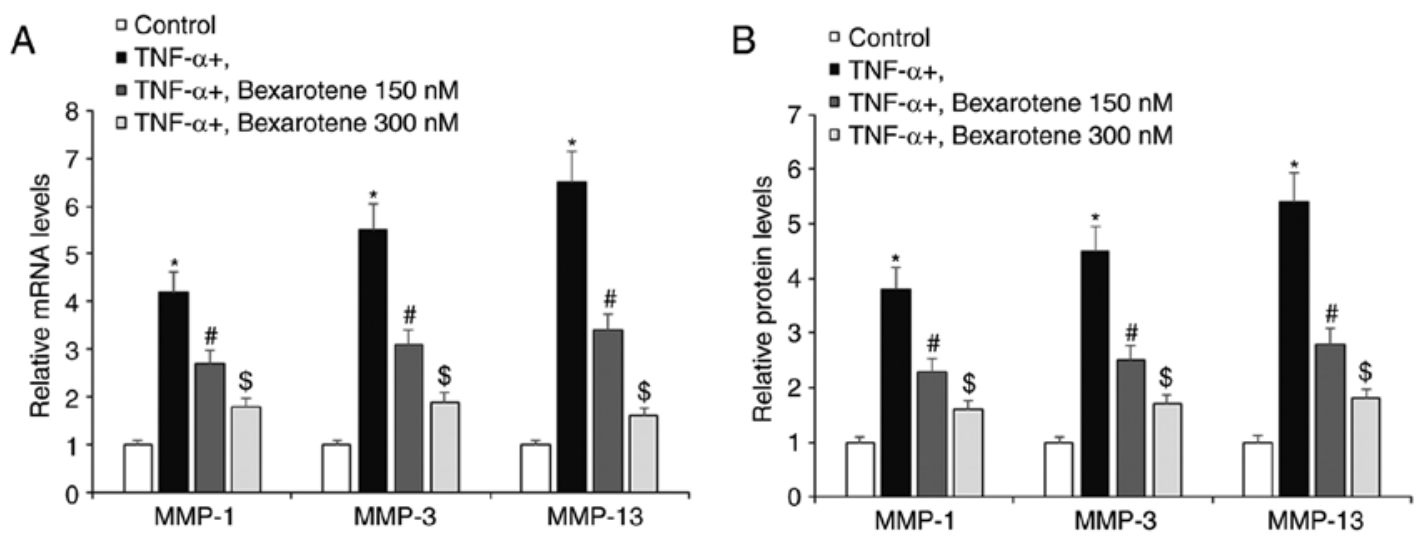

Figure 3. Bexarotene reverses the TNF- $\alpha$-induced expression of MMPs in human FLS. FLS were treated with $10 \mathrm{ng} / \mathrm{ml}$ TNF- $\alpha$ in the presence or absence of 150 and $300 \mathrm{nM}$ bexarotene for $24 \mathrm{~h}$. (A) mRNA expression levels of MMP-1, MMP-3 and MMP-13 were determined by reverse transcription-quantitative PCR analysis. (B) Protein expression levels of MMP-1, MMP-3 and MMP-13 were determined by ELISA analysis. " $\mathrm{P}<0.01$ vs. control; ${ }^{\prime} \mathrm{P}<0.01$ vs. TNF- $\alpha$; and ${ }^{\$} \mathrm{P}<0.01$ vs. TNF- $\alpha+$ bexarotene $150 \mathrm{nM}$. TNF- $\alpha$, tumor necrosis factor- $\alpha$; MMP, matrix metalloproteinase; FLS, fibroblast-like synoviocyte.
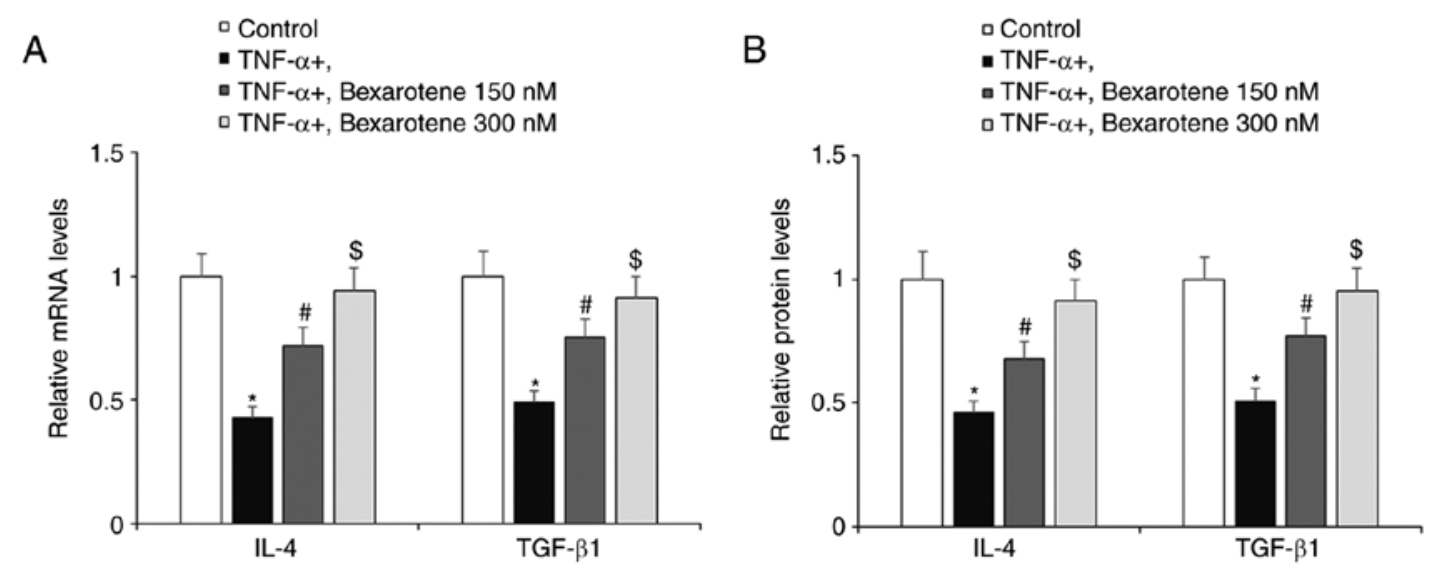

Figure 4. Bexarotene reverses the TNF- $\alpha$-induced reduction of the anti-inflammatory cytokines IL- 4 and TGF- $\beta 1$ in human FLS. FLS were treated with $10 \mathrm{ng} / \mathrm{ml} \mathrm{TNF}-\alpha$ in the presence or absence of 150 and $300 \mathrm{nM}$ bexarotene for $24 \mathrm{~h}$. (A) mRNA expression levels of IL- 4 and TGF- $\beta 1$ were determined by reverse transcription-quantitative PCR analysis. (B) Secreted levels of IL- 4 and TGF- $\beta 1$ were determined by ELISA. ${ }^{*} \mathrm{P}<0.01$ vs. control; ${ }^{*} \mathrm{P}<0.01$ vs. TNF- $\alpha$; and ${ }^{\mathrm{S}} \mathrm{P}<0.01$ vs. TNF- $\alpha+$ bexarotene $150 \mathrm{nM}$. TNF- $\alpha$, tumor necrosis factor- $\alpha$; IL, interleukin; TGF- $\beta 1$, transforming growth factor- $\beta 1$; FLS, fibroblast-like synoviocyte.

Finally, the cellular signaling pathways involved in mediating the effects of RXR agonism were explored. The p38 MAPK pathway is widely studied as a treatment target in RA due to its crucial role in chronic inflammation (24). As shown in Fig. 6, TNF- $\alpha$ stimulation increased the levels of $\mathrm{p}-\mathrm{p} 38$ protein to $\sim$-fold compared with the control unstimulated cells, while 


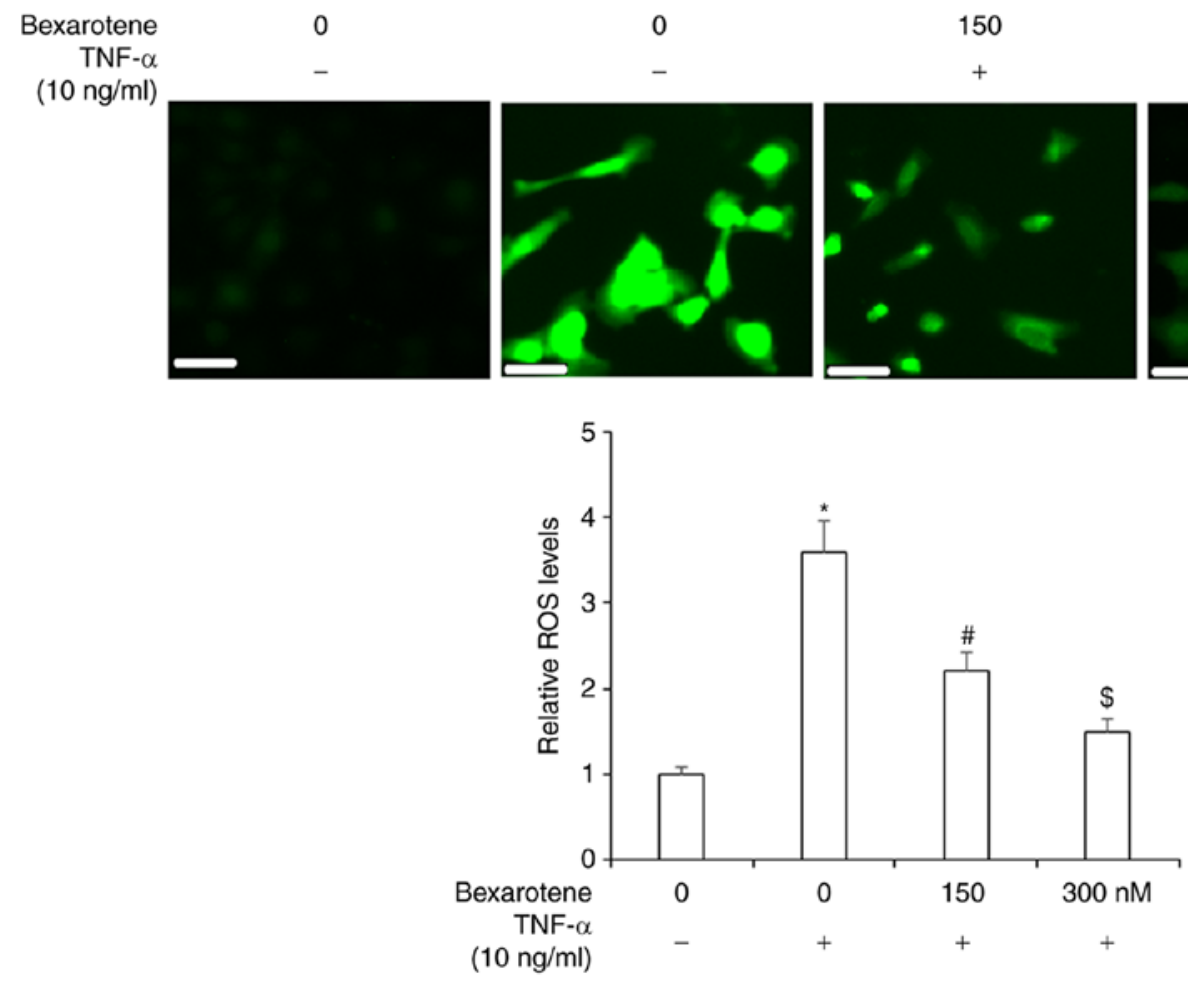

Figure 5. Bexarotene reverses the TNF- $\alpha$-induced oxidative stress in human FLS. FLS were treated with $10 \mathrm{ng} / \mathrm{ml} \mathrm{TNF}-\alpha$ in the presence or absence of 150 and $300 \mathrm{nM}$ bexarotene for $24 \mathrm{~h}$. Production of ROS was measured by the DCFH-DA assay. Scale bar, $50 \mu \mathrm{m}$. " $\mathrm{P}<0.01 \mathrm{vs}$. control; ${ }^{\#} \mathrm{P}<0.01 \mathrm{vs}$. TNF- $\alpha$; and ${ }^{\mathrm{S}} \mathrm{P}<0.01$ vs. TNF- $\alpha+$ bexarotene $150 \mathrm{nM}$. TNF- $\alpha$, tumor necrosis factor- $\alpha$; FLS, fibroblast-like synoviocyte; ROS, reactive oxygen species.
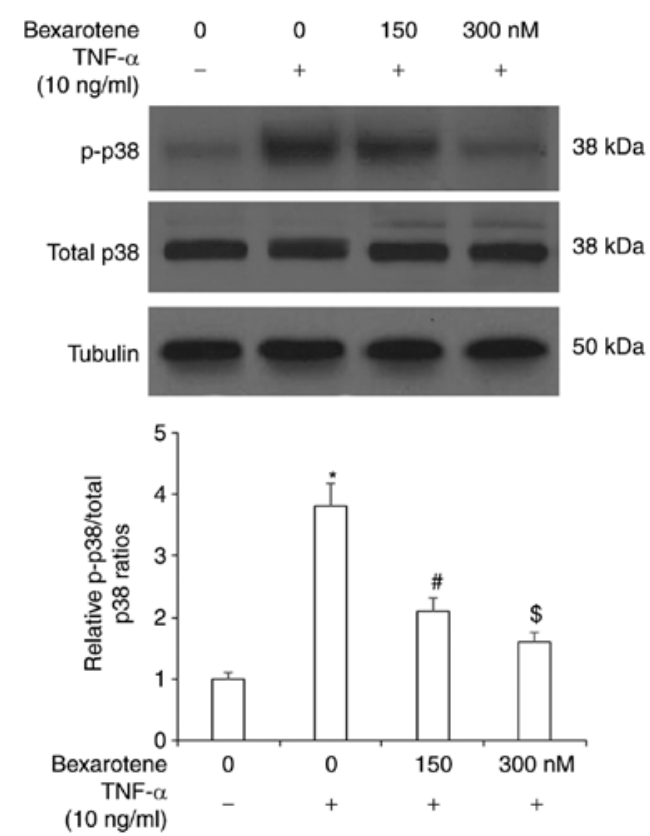

Figure 6. Bexarotene reverses the TNF- $\alpha$-induced activation of p38 mitogen-activated protein kinase in human FLS. FLS were treated with $10 \mathrm{ng} / \mathrm{ml} \mathrm{TNF}-\alpha$ in the presence or absence of 150 and $300 \mathrm{nM}$ bexarotene for $2 \mathrm{~h}$. Total p38 and p-p38 expression levels were determined by western blot analysis. Relative p-p38/total p38 ratios were quantified. ${ }^{*} \mathrm{P}<0.01$ vs. control; ${ }^{\#} \mathrm{P}<0.01$ vs. TNF- $\alpha$; and ${ }^{\$} \mathrm{P}<0.01$ vs. TNF- $\alpha+$ bexarotene $150 \mathrm{nM}$. TNF- $\alpha$, tumor necrosis factor- $\alpha$; FLS, fibroblast-like synoviocyte; $\mathrm{p}-$, phosphorylated.

treatment with bexarotene significantly reduced the levels of p-p38 to $\sim 1.5$-fold. The NF- $\kappa \mathrm{B}$ pathway is regarded as perhaps the most important pathway involved in the inflammatory
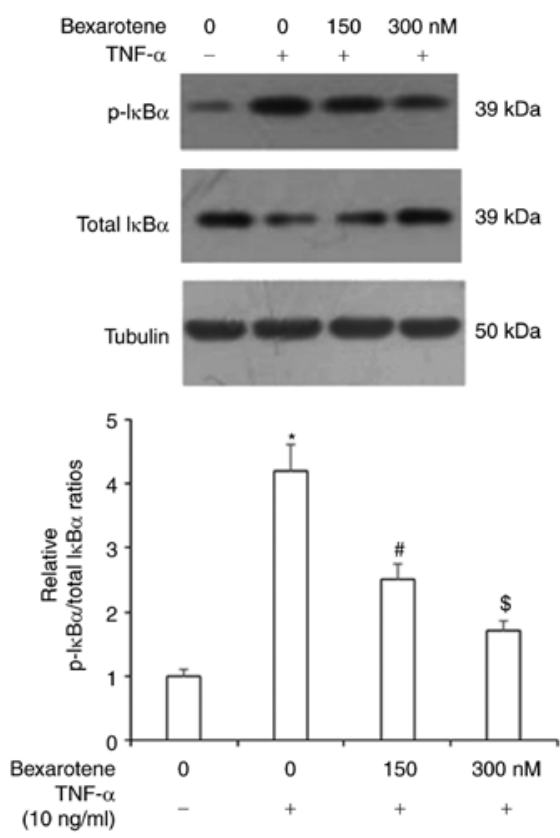

Figure 7. Bexarotene reverses the TNF- $\alpha$-induced phosphorylation of I $\mathrm{B} \alpha$ in human FLS. FLS were treated with $10 \mathrm{ng} / \mathrm{ml}$ TNF- $\alpha$ in the presence or absence of 150 and $300 \mathrm{nM}$ bexarotene for $6 \mathrm{~h}$. Total I $\mathrm{B} \alpha$ and $\mathrm{p}-\mathrm{I} \kappa \mathrm{B} \alpha$ expression levels were determined by western blot analysis. Relative $\mathrm{p}$-IkB $\alpha /$ total IkB $\alpha$ ratios were quantified. ${ }^{*} \mathrm{P}<0.01$ vs. control; ${ }^{\#} \mathrm{P}<0.01$ vs. TNF- $\alpha$; and ${ }^{\$} \mathrm{P}<0.01$ vs. TNF- $\alpha+$ bexarotene $150 \mathrm{nM}$. TNF- $\alpha$, tumor necrosis factor- $\alpha$; Iк $\mathrm{B} \alpha$, inhibitor $\alpha$ of $\kappa \mathrm{B}$; FLS, fibroblast-like synoviocyte; $\mathrm{p}-$, phosphorylated.

response (25). To determine the effects of RXR agonism on $N F-\kappa B$ signaling activation, first, the effect of bexarotene on its inhibitor, I $\mathrm{B} \alpha$, was investigated. As shown in Fig. 7, exposure 

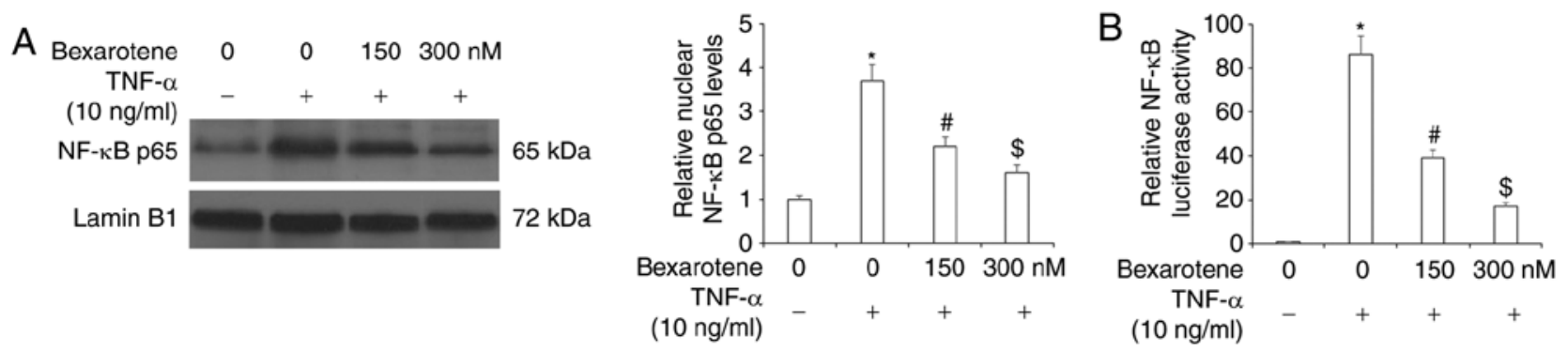

Figure 8. Bexarotene reverses the TNF- $\alpha$-induced activation of NF- $\mathrm{kB}$ in human FLS. FLS were treated with $10 \mathrm{ng} / \mathrm{ml}$ TNF- $\alpha$ in the presence or absence of 150 and $300 \mathrm{nM}$ bexarotene for $6 \mathrm{~h}$. (A) Nuclear levels of NF- $\mathrm{KB}$ p65. Lamin B1 was used as a loading control. (B) Luciferase activity of NF- $\mathrm{B}$. * P<0.01 vs. control; ${ }^{\#} \mathrm{P}<0.01$ vs. TNF- $\alpha$; and ${ }^{\mathrm{S}} \mathrm{P}<0.01$ vs. TNF- $\alpha+$ bexarotene $150 \mathrm{nM}$. TNF- $\alpha$, tumor necrosis factor- $\alpha$; NF- $\kappa \mathrm{B}$, nuclear factor- $\mathrm{B}$; FLS, fibroblast-like synoviocyte.

to TNF- $\alpha$ increased the levels of $\mathrm{p}$-I $\kappa \mathrm{B} \alpha$ to $>4$-fold compared with the control unstimulated cells, but treatment with bexarotene reduced the levels of $\mathrm{p}-\mathrm{I} \kappa \mathrm{B} \alpha$ to $<2$-fold. Similarly, the results of western blot analysis revealed that $\mathrm{TNF}-\alpha$ stimulation increased the levels of nuclear p-65 protein to $\sim 4$-fold, and this effect was reduced to $<2$-fold following bexarotene treatment (Fig. 8A). Luciferase reporter assay revealed that TNF- $\alpha$ stimulation increased $\mathrm{NF}-\kappa \mathrm{B}$ activity by 85 -fold, while treatment with bexarotene significantly reduced the luciferase activity of $\mathrm{NF}-\kappa \mathrm{B}$ in a dose-dependent manner (Fig. 8B). These findings indicated that bexarotene exerted dose-dependent protective effects against insult from TNF- $\alpha$ and that these effects were mediated via the p38 MAPK/I $\mathrm{B} \alpha / \mathrm{NF}-\kappa \mathrm{B}$ pathway.

\section{Discussion}

RA is a painful chronic inflammatory disease for which, despite its high prevalence, a reliable therapy is still not available. Recent studies have focused on targeted agonism/antagonism of specific receptors as a means to modulate the expression of cytokines, chemokines, and degradative enzymes involved in the pathogenesis of RA (26). $\mathrm{RXR}$ is a member of the superfamily of nuclear receptors and functions via homodimerization with itself or heterodimerization with peroxisome proliferator-activated receptors (PPARs) $(27,28)$. Both retinoic acid receptors (RARs) and retinoid $\mathrm{X}$ receptors (RXRs) have $\alpha, \beta$ and $\gamma$ subtypes and interact with retinoids. Retinoids refer to natural or synthetic vitamers of all-trans-retinol (vitamin A), and have long been recognized as having the ability to exert pleiotropic effects, including inhibition of synthesis of MMPs and regulation of the cell cycle, differentiation and apoptosis. While TNF- $\alpha$ is known to induce cell death in many cell types, RA FLS exhibit increased proliferation and resistance to apoptosis in response to TNF- $\alpha$, thereby contributing to their invasive nature $(29,30)$. Bexarotene (Targetrin) is currently the only synthetic rexinoid approved by the FDA for clinical use, but this class of drugs is currently expanding, with new selective RXR ligands with higher specificity and lower side effects under development. Bexarotene is approved for the treatment of T-cell lymphoma and is also being investigated as a potential treatment for breast and lung cancers due to its antiproliferative effects $(31,32)$. To the best of our knowledge, the present study is the first to have investigated the role of RXR agonism by bexarotene in human FLS. First, it was determined that expression of RXR was downregulated in human FLS upon exposure to TNF- $\alpha$, thereby demonstrating a potential treatment target against TNF- $\alpha$-mediated RA progression. Then, the results demonstrated that bexarotene exerted beneficial effects against TNF- $\alpha$-induced markers of RA, by downregulating expression of proinflammatory cytokines, chemokines and collagenases, and by upregulating the expression of protective cytokines. Notably, the present findings revealed that the effects of bexarotene in TNF- $\alpha$-stimulated FLS were mediated through the p38 $\mathrm{MAPK} / \mathrm{NF}-\kappa \mathrm{B}$ pathway.

Previous studies with bexarotene have demonstrated its anti-inflammatory effects. A recent study reported that bexarotene reduced the expression of inflammatory cytokines in a controlled cortical impact mouse model (33). Another recent study found that the formation of PPAR $\alpha / \beta / \gamma-\mathrm{RXR} \alpha$ heterodimers and Cytochrome p450 4F6 expression reduced inflammation-associated hypotension in a septic shock rat model (34). The present results provided further evidence of the anti-inflammatory capacity of bexarotene by demonstrating that bexarotene significantly inhibited TNF- $\alpha$-induced expression of IL-6, IL-8 and HMGB1 in FLS. While agonism of RXRs using bexarotene combination therapy has been shown to decrease the expression of MCP-1 in rat mesangial cells and human umbilical arterial endothelial cells $(35,36)$, the present study is the first to demonstrate the ability of bexarotene to exert this effect in FLS. Previous research using a photoaged skin mouse model did not find any significant effect of RXR agonism on ultraviolet-induced expression of MMP-3 and MMP-13. However, the present findings demonstrated that RXR agonism significantly reduced expression of MMP-1, MMP-3 and MMP-13 induced by TNF- $\alpha$ in FLS (37). The p38 MAPK/NF- $\mathrm{B}$ pathway is widely studied as a treatment target against chronic inflammatory diseases, including RA (38). The involvement of the $\mathrm{p} 38 \mathrm{MAPK} / \mathrm{NF}-\kappa \mathrm{B}$ pathway in the anti-inflammatory effects of RXR was demonstrated in an earlier study using a combination of PPAR $\gamma$ and RXR ligands (39). RXR has also been shown to modulate $\mathrm{NF}-\kappa \mathrm{B}$ activation (40). The present results demonstrated that RXR agonism with bexarotene suppressed activation of the p38 MAPK/NF- $\mathrm{B}$ pathway by preventing phosphorylation of $\mathrm{p} 38$ and $\mathrm{I} \kappa \mathrm{B} \alpha$, as well as reducing p65 protein levels in the nucleus. These findings suggested that RXR agonism using bexarotene may exert novel protective effects against the development and progression of RA induced by TNF- $\alpha$. 


\section{Acknowledgements}

Not applicable.

\section{Funding}

This study was funded by the First Affiliated Hospital of Henan University of Science and Technology.

\section{Availability of data and materials}

The datasets used and/or analyzed during the present study are available from the corresponding author on reasonable request.

\section{Authors' contributions}

YL contributed to the conception and design of the study. YL, QX, YW, LZ, PZ, XH and JW contributed to data acquisition, data analysis and interpretation. YL drafted and critically revised the article. All authors agreed to be accountable for all aspects of the work in ensuring that questions related to the accuracy or integrity of the work are appropriately investigated and resolved. All authors read and approved the final manuscript.

\section{Ethics approval and consent to participate}

Experimental procedures were approved by the Institutional Ethics Committee at the First Affiliated Hospital of Henan University of Science and Technology. Written informed consent was obtained from all of the participants.

\section{Patient consent for publication}

Not applicable.

\section{Competing interests}

The authors declare that they have no competing interests.

\section{References}

1. Sweeney SE and Firestein GS: Rheumatoid arthritis: Regulation of synovial inflammation. Int J Biochem Cell Biol 36: 372-378, 2004

2. Pap T and Korb-Pap A: Cartilage damage in osteoarthritis and rheumatoid arthritis-two unequal siblings. Nat Rev Rheumatol 11: 606-615, 2015.

3. Bresnihan B: Pathogenesis of joint damage in rheumatoid arthritis. J Rheumatol 26: 717-719, 1999.

4. Bartok B and Firestein GS: Fibroblast-like synoviocytes: Key effector cells in rheumatoid arthritis. Immunol Rev 233: 233-255, 2010.

5. Nanki T, Nagasaka K, Hayashida K, Saita Y and Miyasaka N: Chemokines regulate IL- 6 and IL-8 production by fibroblast-like synoviocytes from patients with rheumatoid arthritis. J Immunol 167: 5381-5385, 2001.

6. Georganas C, Liu H, Perlman H, Hoffmann A, Thimmapaya B and Pope RM: Regulation of IL- 6 and IL-8 expression in rheumatoid arthritis synovial fibroblasts: The dominant role for NF-kappa B but not C/EBP beta or c-Jun. J Immunol 165: 7199-7206, 2000.

7. Yokota K, Miyazaki T, Hirano M, Akiyama Y and Mimura T: Simvastatin inhibits production of interleukin 6 (IL-6) and IL-8 and cell proliferation induced by tumor necrosis factor-alpha in fibroblast-like synoviocytes from patients with rheumatoid arthritis. J Rheumatol 33: 463-471, 2006.
8. Harigai M, Hara M, Yoshimura T, Leonard EJ, Inoue K and Kashiwazaki S: Monocyte chemoattractant protein-1 (MCP-1) in inflammatory joint diseases and its involvement in the cytokine network of rheumatoid synovium. Clin Immunol Immunopathol 69: 83-91, 1993.

9. Green MJ, Gough AK, Devlin J, Smith J, Astin P, Taylor D and Emery P: Serum MMP-3 and MMP-1 and progression of joint damage in early rheumatoid arthritis. Rheumatology (Oxford) 42: 83-88, 2003.

10. Agere SA, Akhtar N, Watson JM and Ahmed S: RANTES/CCL5 induces collagen degradation by activating MMP-1 and MMP-13 expression in human rheumatoid arthritis synovial fibroblasts. Front Immunol 8: 1341, 2017.

11. Lubberts E, Joosten LA, Chabaud M, van den Bersselaar L, Oppers B, Coenen-de Roo CJ, Richards CD, Miossec P and van den Berg WB: IL-4 gene therapy for collagen arthritis suppresses synovial IL-17 and osteoprotegerin ligand and prevents bone erosion. J Clin Invest 105: 1697-1710, 2000.

12. Chemel M, Brion R, Segaliny A, Lamora A, Charrier C, Brulin B, Maugars Y, Le Goff B, Heymann D and Verrecchia F: Bone morphogenetic protein 2 and transforming growth factor- $\beta 1$ inhibit the expression of the pro-inflammatory cytokine IL-34 in rheumatoid arthritis synovial fibroblasts. Am J Pathol 187: 156-162, 2017.

13. Sugiura Y, Niimi T, Sato S, Yoshinouchi T, Banno S, Naniwa T, Maeda H, Shimizu S and Ueda R: Transforming growth factor $\beta 1$ gene polymorphism in rheumatoid arthritis. Ann Rheum Dis 61: 826-828, 2002.

14. Mateen S,Zafar A, Moin S, Khan AQ and Zubair S: Understanding the role of cytokines in the pathogenesis of rheumatoid arthritis. Clin Chim Acta 455: 161-171, 2016.

15. Kageyama Y, Takahashi M, Ichikawa T, Torikai E and Nagano A: Reduction of oxidative stress marker levels by anti-TNF-alpha antibody, infliximab, in patients with rheumatoid arthritis. Clin Exp Rheumatol 26: 73-80, 2008.

16. Charles P, Elliott MJ, Davis D, Potter A, Kalden JR, Antoni C, Breedveld FC, Smolen JS, Eberl G, deWoody K, et al: Regulation of cytokines, cytokine inhibitors, and acute-phase proteins following anti-TNF-alpha therapy in rheumatoid arthritis. J Immunol 163: 1521-1528, 1999

17. Gottenberg JE, Brocq O, Perdriger A, Lassoued S, Berthelot JM, Wendling D, Euller-Ziegler L, Soubrier M, Richez C, Fautrel B, et al: Non-TNF-targeted biologic vs. a second anti-TNF drug to treat rheumatoid arthritis in patients with insufficient response to a first anti-TNF drug: A randomized clinical trial. JAMA 316: 1172-1180, 2016.

18. Li L, Liu Y, Wang J, Chen L, Zhang W and Yan X: Preparation, in vitro and in vivo evaluation of bexarotene nanocrystals with surface modification by folate-chitosan conjugates. Drug Deliv 23: 79-87, 2016.

19. Yen WC, Prudente RY, Corpuz MR, Negro-Vilar A and Lamph WW: A selective retinoid $\mathrm{X}$ receptor agonist bexarotene (LGD1069, targretin) inhibits angiogenesis and metastasis in solid tumours. Br J Cancer 94: 654-660, 2006.

20. Yamanishi Y, Boyle DL, Green DR, Keystone EC, Connor A, Zollman S and Firestein GS: P53 tumor suppressor gene mutations in fibroblast-like synoviocytes from erosion synovium and non-erosion synovium in rheumatoid arthritis. Arthritis Res Ther 7: R12-R18, 2005.

21. Livak KJ and Schmittgen TD: Analysis of relative gene expression data using real-time quantitative PCR and the 2(-Delta Delta C(T)) method. Methods 25: 402-408, 2001.

22. Terraneo L, Bianciardi P, Malavalli A, Mkrtchyan G, Spann SN, Lohman J, Samaja $M$ and Vandegriff KD: Hemoglobin extravasation in the brain of rats exchange-transfused with hemoglobin-based oxygen carriers. Artif Cells Nanomed Biotechnol 45: 710-716, 2017.

23. Ma S, Bai Z, Wu H and Wang W: The DPP-4 inhibitor saxagliptin ameliorates ox-LDL-induced endothelial dysfunction by regulating AP-1 and NF-кB. Eur J Pharmacol 851: 186-193, 2019.

24. Schett G, Zwerina J and Firestein G: The p38 mitogen-activated protein kinase (MAPK) pathway in rheumatoid arthritis. Ann Rheum Dis 67: 909-916, 2008.

25. Mitchell JP and Carmody RJ: NF- $\kappa \mathrm{B}$ and the transcriptional control of inflammation. Int Rev Cell Mol Biol 335: 41-84, 2018.

26. Noack M and Miossec P: Selected cytokine pathways in rheumatoid arthritis. Semin Immunopathol 39: 365-383, 2017.

27. Emdad L, Das SK, Hu B, Kegelman T, Kang DC, Lee SG, Sarkar D and Fisher PB: AEG-1/MTDH/LYRIC: A promiscuous protein partner critical in cancer, obesity, and CNS diseases. Adv Cancer Res 131: 97-132, 2016. 
28. Chiazza F and Collino M: Peroxisome proliferator-activated receptors (PPARs) in glucose control. Mol Nutri Diabetes: 105-114, 2016.

29. Vincenti MP, Clark IM and Brinckerhoff CE: Using inhibitors of metalloproteinases to treat arthritis. Easier said than done? Arthritis Rheum 37: 1115-1126, 1994.

30. Mosquera N, Rodriguez-Trillo A, Mera-Varela A, Gonzalez A and Conde C: Uncovering Cellular retinoic acid-binding protein 2 as a potential target for rheumatoid arthritis synovial hyperplasia. Sci Rep 8: 8731, 2018.

31. Uray IP and Brown PH: Chemoprevention of hormone receptor-negative breast cancer: New approaches needed. Recent Results Cancer Res 188: 147-162, 2011.

32. Zhang D, Leal AS, Carapellucci S, Zydeck K, Chaaban N, Sporn MB, Wagner CE and Liby KT: Comparison of the rexinoids Bexarotene and Pyrimidine-Bexarotene in a preclinical model of lung carcinogenesis. FASEB J 31 (Suppl 1): S671-S616, 2017.

33. Zhong J, Cheng C, Liu H, Huang Z, Wu Y, Teng Z, He J, Zhang $\mathrm{H}, \mathrm{Wu} \mathrm{J}$, Cao F, et al: Bexarotene protects against traumatic brain injury in mice partially through apolipoprotein $\mathrm{E}$. Neuroscience 343: 434-448, 2017.

34. Tunctan B, Kucukkavruk SP, Temiz-Resitoglu M, Guden DS, Sari AN and Sahan-Firat S: Bexarotene, a selective RXRa agonist, reverses hypotension associated with inflammation and tissue injury in a rat model of septic shock. Inflammation 41: $337-355,2018$.
35. Kim DH, Lee GC, Kim CH, Oh SW, Han KH and Han SY: Anti-inflammatory effect of combination therapy with rosiglitazone and all-trans retinoic acid on high glucose-induced MCP-1 response in rat mesangial cells. Biomed Res 28: 463-467, 2017.

36. Escudero P, Martinez de Marañón A, Collado A, GonzalezNavarro H, Hermenegildo C, Peiró C, Piqueras L and Sanz MJ: Combined sub-optimal doses of rosuvastatin and bexarotene impair angiotensin II-induced arterial mononuclear cell adhesion through inhibition of Nox5 signaling pathways and increased RXR/PPAR $\alpha$ and RXR/PPAR $\gamma$ interactions. Antioxid Redox Signal 22: 901-920, 2015.

37. Li Z, Niu X, Xiao S and Ma H: Retinoic acid ameliorates photoaged skin through RAR-mediated pathway in mice. Mol Med Rep 16: 6240-6247, 2017.

38. Westra $\mathrm{J}$ and Limburg PC: p38 mitogen-activated protein kinase (MAPK) in rheumatoid arthritis. Mini Rev Med Chem 6: 867-874, 2006.

39. Desreumaux P, Dubuquoy L, Nutten S, Peuchmaur M, Englaro W, Schoonjans K, Derijard B, Desvergne B, Wahli W, Chambon P, et al: Attenuation of colon inflammation through activators of the retinoid X receptor (RXR)/peroxisome proliferator-activated receptor gamma (PPARgamma) heterodimer: A basis for new therapeutic strategies. J Exp Med 193: 827-838, 2001.

40. Fan Y, Wang J, Wei L, He B, Wang C and Wang B: Iron deficiency activates pro-inflammatory signaling in macrophages and foam cells via the p38 MAPK-NF- $\kappa$ B pathway. Int J Cardiol 152: 49-55, 2011 